\title{
$N$-(5-Morpholino-2-arylimidazo[2,1-b][1,3,4]thiadiazol-6- yl)carboxamides as Potential Fer/FerT Kinase Inhibitors. Homology Modeling, Molecular Docking Studies and In Silico ADMET Profiling
}

\author{
Pavlo V. Zadorozhnii ${ }^{1, *}$ (D), Vadym V. Kiselev ${ }^{1(\mathbb{D})}$, Valeriia V. Pavlova ${ }^{1(1)}$, \\ Aleksandr V. Kharchenko ${ }^{1}$ (i), Oxana V. Okhtina ${ }^{1}$ (iD \\ 1 Department of pharmacy and technology of organic substances, Ukrainian State University of Chemical Technology, \\ Gagarin Ave., 8, Dnipro 49005, Ukraine \\ * Correspondence: torfp@i.ua (P.V.Z.);
}

Scopus Author ID 56560170200

Received: 4.02.2021; Revised: 5.03.2021; Accepted: 9.03.2021; Published: 22.03.2021

\begin{abstract}
This study has comparatively evaluated the degree of affinity of $N$-(5-morpholino-2arylimidazo[2,1-b][1,3,4]thiadiazol-6-yl)carboxamides $2 \mathrm{a}-\mathrm{f}$ and 6-(4-isopropylphenyl)-2-(4-((4methylpiperazin-1-yl)methyl)piperidin-1-yl)imidazo[2,1-b][1,3,4]thiadiazole (E260) to Fer kinase using molecular modeling methods. The Fer kinase model has been generated by homology modeling. It has been shown that compounds $2 \mathrm{a}-\mathrm{f}$ predominantly form stronger complexes with this enzyme than the reference drug E260. In silico ADMET prediction of the properties of compounds 2a-f and E260 has been carried out. Comparative analysis of the obtained results has shown that compounds $2 \mathrm{a}-\mathrm{f}$ are not inferior to the reference drug - E260 and even surpass it in most parameters. All examined compounds 2a-f have shown good results under in silico experimental conditions and can be recommended for further study on tumor cell cultures.
\end{abstract}

Keywords: in silico; ADMET; molecular docking; imidazo[2,1-b][1,3,4]thiadiazole; Fer kinase.

(C) 2021 by the authors. This article is an open-access article distributed under the terms and conditions of the Creative Commons Attribution (CC BY) license (https://creativecommons.org/licenses/by/4.0/).

\section{Introduction}

Derivatives of imidazo[2,1-b][1,3,4]thiadiazoles are widely described in the scientific literature and are of great interest for organic and medicinal chemistry as well as pharmacy [1$3]$. Compounds containing the imidazo[2,1-b][1,3,4]thiadiazole cycle have antibacterial activity [4-6]. Some of them can suppress quorum sensing [7,8] and prevent the formation of biofilms [9]. Some derivatives of this compounds have antifungal [4,10,11], anti-tuberculosis [11-13], antiviral [14], anti-inflammatory [15], hypoglycemic [16], antithrombotic [17], antiAlzheimer [18] and other types of biological activity [1-3]. Over the past ten years, many works have appeared on the antitumor activity of these compounds [19-28].

Recently, the research group of Professor Nir U. has shown that the imidazo[2,1$b][1,3,4]$ thiadiazole derivative, E260 (6-(4-isopropylphenyl)-2-(4-((4-methylpiperazin-1yl)methyl)piperidin-1-yl)imidazo[2,1- $b][1,3,4]$ thiadiazole), effectively inhibits Fer and FerT (which is specific for cancer cells) kinases, leading to selective death of malignant cells and suppression of their growth in vivo [29]. Fer kinase is found in the cytoplasm, nucleus [30], 
and mitochondria of malignant cells [31]. In mitochondria, Fer and FerT are associated with complex I of the electron transport chain (ETC) of a malignant but abnormal somatic cell. In this case, Fer and FerT support ATP production in cancer cells. Fer and/or FerT suppression leads to disruption of the ETC complex I activity and disrupts ATP synthesis in malignant cells [31]. All this makes Fer/FerT a very promising target for cancer therapy.

Earlier, we reported on the synthesis of a series of $N$-(5-morpholino-2-arylimidazo[2,1b][1,3,4]thiadiazol-6-yl)carboxamides 2 [32,33] based on $N$-(2,2,2-trichloro-1-((5-aryl-1,3,4thiadiazol-2-yl)amino)ethyl)carboxamides $1[33,34]$ (Scheme 1). Products 2 were obtained in acceptable yields. The closure of the imidazole ring occurred through the formation of intermediates $\mathrm{A}$ and $\mathrm{B}$.<smiles>[R]C(=O)NC(Nc1nnc([Al])s1)C(Cl)(Cl)Cl</smiles><smiles>[R]C(=O)Nc1nc2sc([Al])nn2c1N1CCOCC1</smiles>

2 yield $32-58 \%$

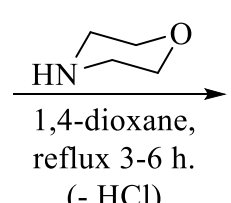

$(-\mathrm{HCl})$

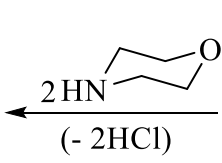<smiles>[R]C(=O)NC(Nc1nnc([AlH2])s1)=C(Cl)Cl</smiles><smiles>C1CNCCOC1</smiles><smiles>[R]C(=O)N[C@H](/N=c1\[nH]nc([AlH2])s1)/C(Cl)=[N+](/Cl)CCCC</smiles>

$\mathrm{R}=\mathrm{CH}_{3}, \mathrm{Ar}=p-\mathrm{CH}_{3} \mathrm{C}_{6} \mathrm{H}_{4}(\mathbf{a}) ; \mathrm{R}=\mathrm{C}_{6} \mathrm{H}_{5}, \mathrm{Ar}=p-\mathrm{CH}_{3} \mathrm{C}_{6} \mathrm{H}_{4}(\mathbf{b}) ; \mathrm{R}=p-\mathrm{CH}_{3} \mathrm{C}_{6} \mathrm{H}_{4}, \mathrm{Ar}=\mathrm{C}_{6} \mathrm{H}_{5}$ (c); $\mathrm{R}=p-\mathrm{CH}_{3} \mathrm{C}_{6} \mathrm{H}_{4}, \mathrm{Ar}=p-\mathrm{CH}_{3} \mathrm{C}_{6} \mathrm{H}_{4}(\mathbf{d}) ; \mathrm{R}=p-\mathrm{CH}_{3} \mathrm{C}_{6} \mathrm{H}_{4}, \mathrm{Ar}=m-\mathrm{BrC}_{6} \mathrm{H}_{4}(\mathbf{e}) ; \mathrm{R}=p-\mathrm{CH}_{3} \mathrm{C}_{6} \mathrm{H}_{4}, \mathrm{Ar}=m-\mathrm{NO}_{2} \mathrm{C}_{6} \mathrm{H}_{4}(\mathbf{f})$.

Scheme 1. Synthesis of $N$-(5-morpholino-2-arylimidazo[2,1-b][1,3,4]thiadiazol-6-yl)carboxamides (2).

The main goal of this work is to search for potential Fer/FerT inhibitors among the previously obtained $\quad N$-(5-morpholino-2-arylimidazo[2,1- $b][1,3,4]$ thiadiazol-6yl)carboxamides 2 using molecular docking research [35,36].

\section{Materials and Methods}

\subsection{Protein model building.}

To create a three-dimensional Fer kinase model, the homologous modeling method ProMod3 has been used, implemented in the SWISS-MODEL online server [37] (supporting information Figure S1). This enzyme's amino acid sequence was taken from the UniProt open database [38] (UniProt ID: P16591). The crystal structure of human tyrosine-protein kinase Fes/Fps (PDB ID: 6JMF) was used as a template [39]. The structure of the resulting model was optimized using the YASARA online server [40]. To analyze the resulting model's validity, we used the SWISS-MODEL online server, the Structure Assessment function. The resulting model used the amino acid residue numbering automatically generated by SWISS-MODEL (supporting information Figure S2). 


\subsection{Ligand preparation.}

Before molecular docking, the structures of all studied $\mathrm{N}$-(5-morpholino-2arylimidazo[2,1-b][1,3,4]thiadiazol-6-yl)carboxamides (2) and E260 were optimized within the framework of the semiempirical PM3 method [41] using the ArgusLab 4.0.1 software package [42-50] (supporting information Figure S3).

\subsection{Molecular docking studies.}

For all targets, molecular docking was performed using AutoDock Vina [51] implemented in the PyRx 0.8 software package. The lowest energy conformation was chosen as the most likely binding site. Molecular docking was carried out blindly. The grid size was X: 48.7 Y: $61.4 \mathrm{Z}: 80.3 \AA$ A centered at X: $-17.4 \mathrm{Y}: 23.6 \mathrm{Z}: 18.7 \AA$. The conversion of files from the pdbqt to pdb format was performed using Open Babel [52]. The results were visualized using the PyMOL 0.99rc6 program [53].

\subsection{In silico ADMET studies.}

In silico assessment of the ADMET properties of the analyzed compounds was carried out using the admetSAR 2.0 online server [54,55]. This server uses QSAR/SAR models for forecasting based on reliable, open-source databases and full-text peer-reviewed scientific publications. The structures of all analyzed compounds were loaded in the "SMILES" format. The conversion was performed using Open Babel [52]. The results were saved by "copy-paste" operations. To predict new compounds' ADMET properties, admetSAR 2.0 uses 22 qualitative classification models and 5 quantitative regression models. In addition to the forecast result (+ or -), qualitative classification models also provide the probability value of observing this effect in an experiment. The resulting probability value must be above 0.5 . To assess the reliability of the results obtained, admetSAR 2.0 uses the concept of an applicability domain, which is determined by several physicochemical and topological properties.

\section{Results and Discussion}

\subsection{Model of Fer kinase.}

Fer is a non-transmembrane receptor tyrosine kinase from the Fes family [39]. This enzyme is represented by one polypeptide chain, consisting of 367 amino acid residues. We have obtained the Fer kinase model by homology modeling based on the crystal structure of human tyrosine-protein kinase Fes/Fps (PDB ID: 6JMF) [39]. The sequence identity of the Fer kinase and template was $67.30 \%$ (supporting information Figure S2). In the resulting model, $97.82 \%$ of the amino acids are in the Ramachandran plot's preferred regions (Figure 1b), and $2.18 \%$ are in the allowable regions. 
(a)

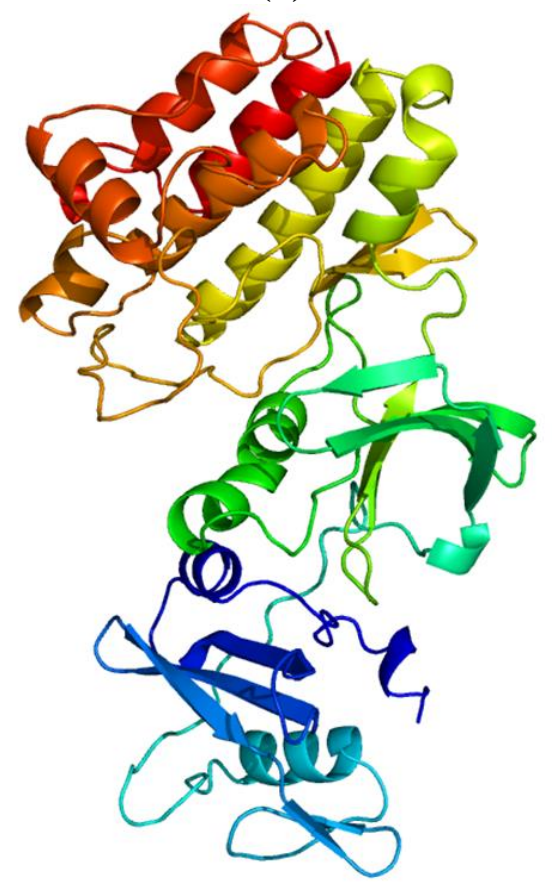

(b)

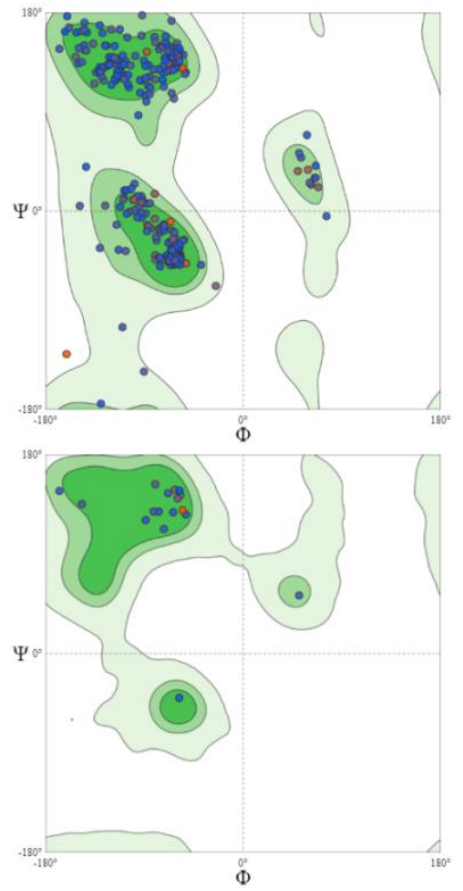

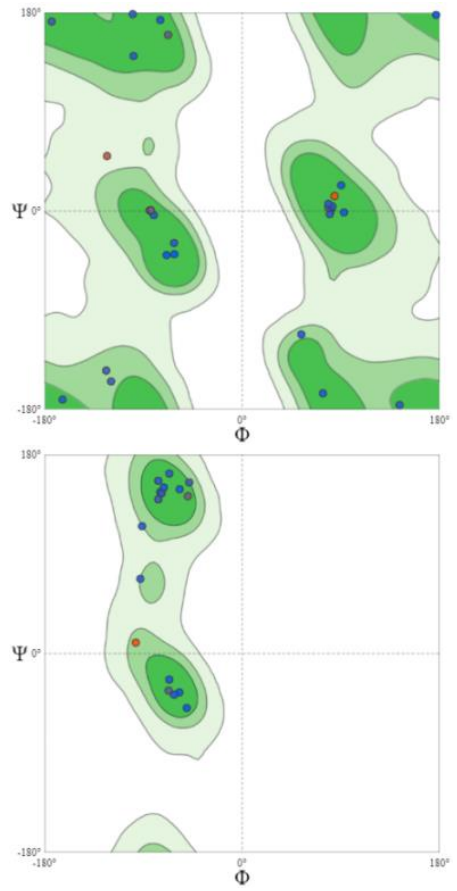

Figure 1. (a) Model of Fer kinase obtained by homologous modeling; (b) Ramachandran plot for the resulting model, $97.82 \%$ of the amino acids are in the preferred regions of the Ramachandran plot, and $2.18 \%$ are in the allowed ones.

\subsection{Molecular docking studies.}

Molecular docking of E260 with the resulting Fer kinase model was carried out blindly. This made it possible to establish the binding site's localization in the enzyme molecule (Figure 2a). E260 interacts with amino acids of the Fer kinase active site through hydrophobic contacts and intermolecular hydrogen bonds with the Arg 688 amino acid ( $3.2 \AA$ bond length) and Asn 573 (3.2 $\AA$ bond length) amino acid (Figure 2b). The energy of the E260-Fer kinase complex was $-7.9 \mathrm{kcal} / \mathrm{mol}$.
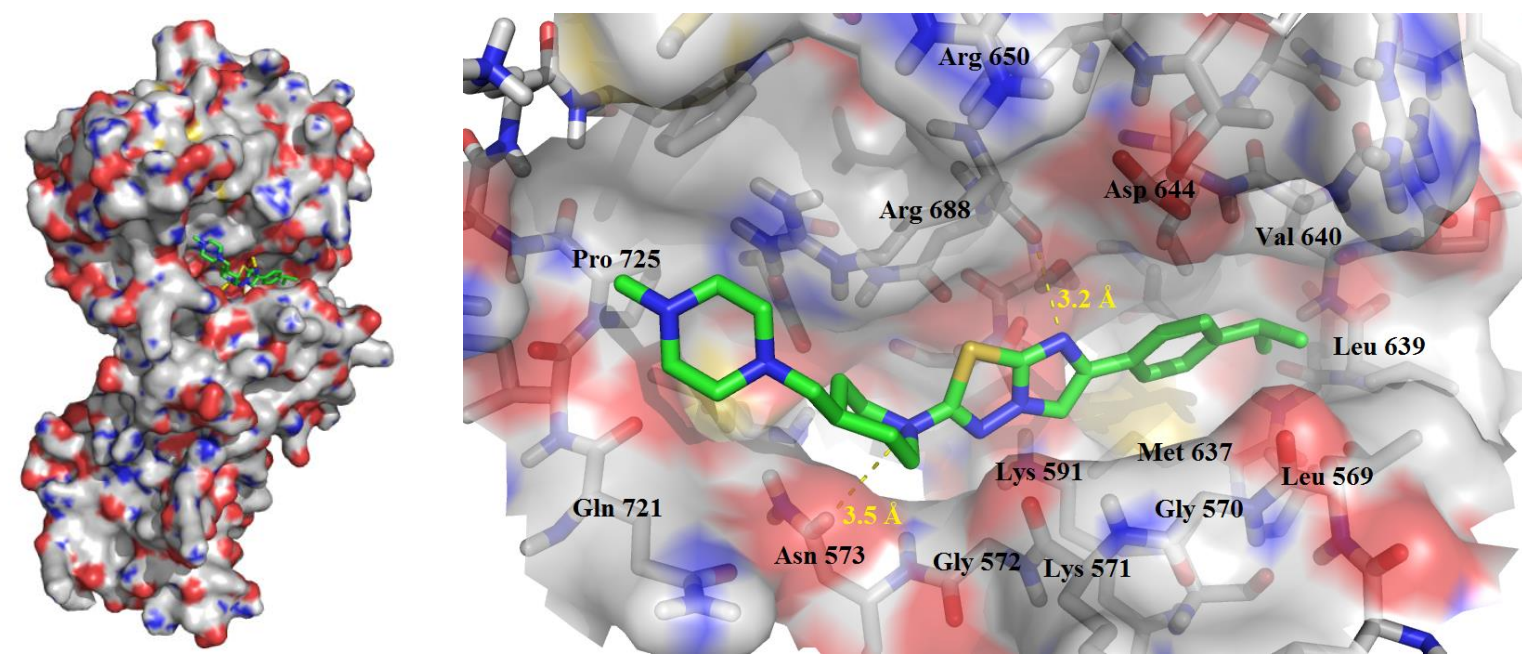

Figure 2. Position of the 6-(4-isopropylphenyl)-2-(4-((4-methylpiperazin-1-yl)methyl)piperidin-1yl)imidazo[2,1-b][1,3,4]thiadiazole (E260) in the active site of Fer kinase according to molecular docking results.

According to the results of blind docking, all analyzed $\mathrm{N}$-(5-morpholino-2arylimidazo[2,1-b][1,3,4]thiadiazol-6-yl)carboxamides (2a-f) interacted with the active site of the Fer kinase (supporting information Figure S3) and surpassed E260 in the strength of the 
complex formed. The exception was $N$-(5-morpholino-2-( $p$-tolyl)imidazo[2,1$b][1,3,4]$ thiadiazol-6-yl)acetamide (2a), for which the energy of the complex with Fer kinase as well as in the case of E260 was $-7.9 \mathrm{kcal} / \mathrm{mol}$. The molecule of compound 2a was additionally fixed in the enzyme's active site due to two hydrogen bonds with the amino acid Asp 702, the length of which was 3.1 and $3.3 \AA$ (Figure 3).
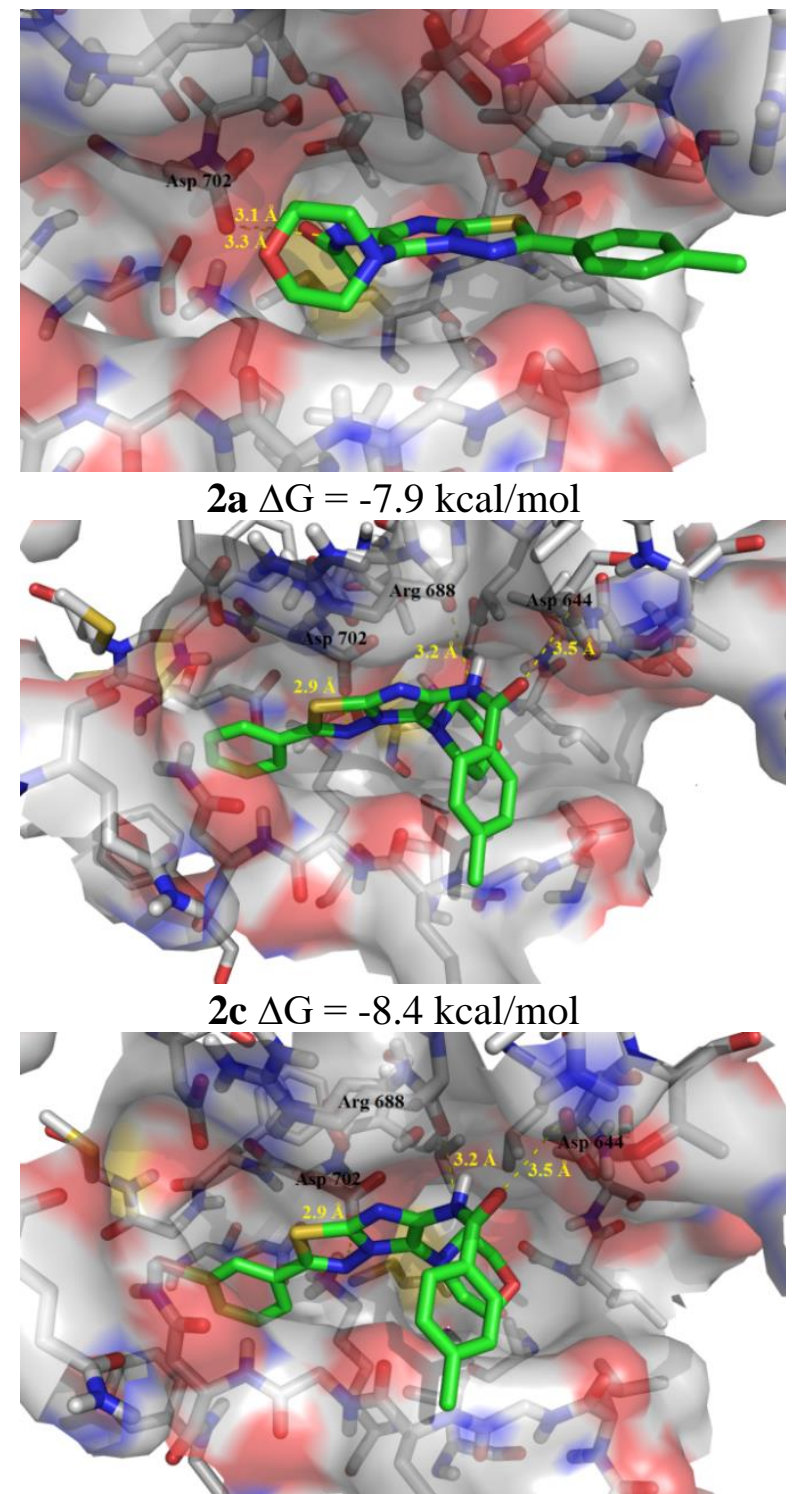

2e $\Delta \mathrm{G}=-8.5 \mathrm{kcal} / \mathrm{mol}$

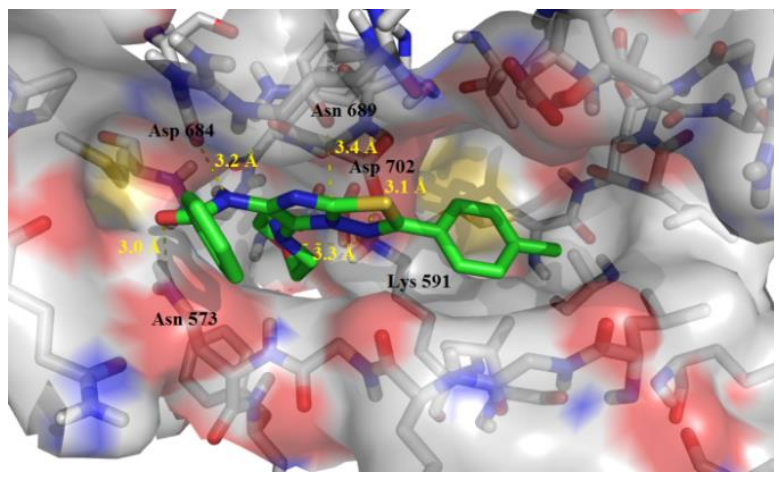

2b $\Delta \mathrm{G}=-8.8 \mathrm{kcal} / \mathrm{mol}$

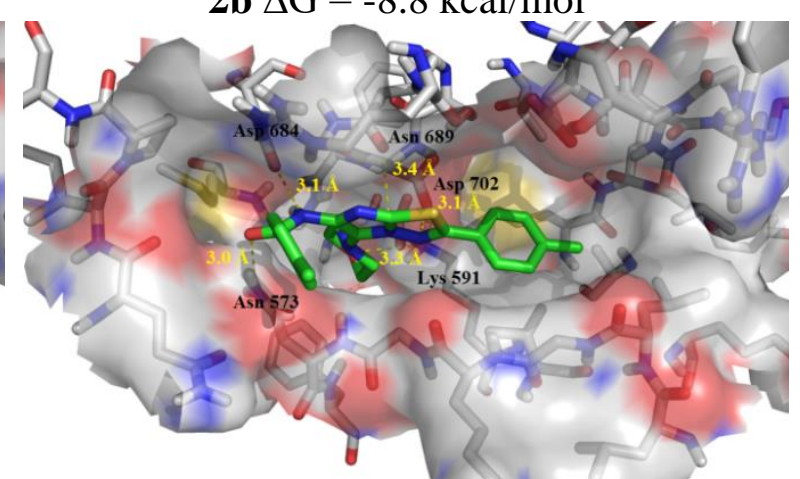

2d $\Delta \mathrm{G}=-8.8 \mathrm{kcal} / \mathrm{mol}$

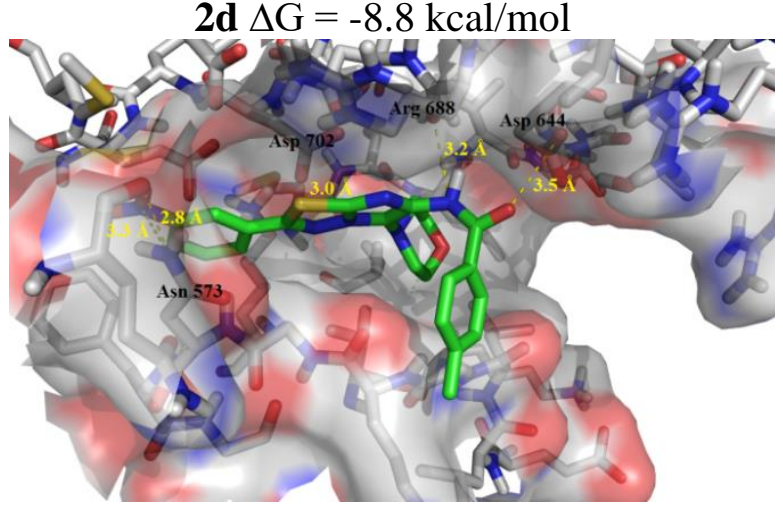

2f $\Delta \mathrm{G}=-8.9 \mathrm{kcal} / \mathrm{mol}$

Figure 3. Position of $N$-(5-morpholino-2-arylimidazo[2,1-b][1,3,4]thiadiazol-6-yl)carboxamides (2a-f) in the active site of Fer kinase according to molecular docking results.

The molecule of $N$-(5-morpholino-2-( $p$-tolyl)imidazo[2,1-b][1,3,4]thiadiazol-6yl)benzamide ( $2 b$ ) was fixed in the active site of the Fer kinase not only due to hydrophobic interactions but also due to five intermolecular hydrogen bonds with amino acids Asn 573 (bond length - $3.0 \AA$ ), Asp 684 (bond length - $3.2 \AA$ ), Asn 689 (bond length - $3.4 \AA$ ), Asp 702 (bond length - $3.4 \AA$ ) and Lys 591 (bond length - $3.3 \AA$ ). The energy of the 2 b-Fer complex was $-8.8 \mathrm{kcal} / \mathrm{mol}$. In the case of 4-methyl- $N$-(5-morpholino-2-phenylimidazo[2,1b] $[1,3,4]$ thiadiazol-6-yl)benzamide $\quad$ (2c) and $\quad N$-(2-(3-bromophenyl)-5morpholinoimidazo[2,1-b][1,3,4]thiadiazol-6-yl)-4-methylbenzamide (2e) additional fixation in the active site cavity occurred due to three intermolecular hydrogen bonds formed with the participation of amino acids Asp 702 (bond length - $2.9 \AA$ ), Arg 688 (bond length - $3.2 \AA$ ), and 
Asp 644 (bond length - $3.5 \AA$ ). The energies of the complexes were -8.4 and $-8.5 \mathrm{kcal} / \mathrm{mol}$, respectively. The molecule of 4-methyl- $N$-(5-morpholino-2-(3-nitrophenyl)imidazo[2,1b] $[1,3,4]$ thiadiazol-6-yl)benzamide (2d) was additionally fixed in the active site of the Fer kinase due to five intermolecular hydrogen bonds with amino acids Asn 573 (bond length - 3.0 $\AA$ ), Asp 684 (bond length - 3.1 ), Asn 689 (bond length - $3.4 \AA$ ), Asp 702 (bond length - 3.1 $\AA$ ), and Lys 591 (bond length - $3.3 \AA$ ). The energy of the 2d-Fer kinase complex was -8.8 $\mathrm{kcal} / \mathrm{mol}$. The best docking results were shown by 4-methyl- $N$-(5-morpholino-2-(3nitrophenyl)imidazo[2,1- $b][1,3,4]$ thiadiazol-6-yl)benzamide (2f); its energy complex with Fer was $-8.9 \mathrm{kcal} / \mathrm{mol}$. The molecule of compound $2 \mathrm{f}$ was additionally fixed in the active site of the enzyme due to five intermolecular hydrogen bonds with amino acids Asn 573 (two bonds 2.8 and 3.3 A long), Asp 702 (bond length - 3.0 ̊), Arg 688 (bond length - $3.2 \AA$ ) and Asp 644 (bond length - $3.5 \AA$ ).

A detailed analysis of intermolecular interactions between the amino acid residues of the Fer kinase's active site and the molecules of compounds 2a-f and E260 indicated an essential role of polar contacts in ligand fixation. A clear relationship was observed between the number of intermolecular hydrogen bonds and the strength of the complex formed. Most likely, hydrophobic interactions do not play a significant role in the fixation of these ligands.

\subsection{In silico ADMET studies.}

When predicting the biological properties of small molecules using QSAR models, first of all, the question is about the reliability of the results obtained. The applicability of a specific QSAR model for predicting the properties of analyzed compounds primarily depends on the degree of their similarity with compounds from the training sample. admetSAR uses the concept of applicability domain to assess the reliability of the results of predicting the properties of new molecules [54]. The applicability domain defines the region of molecular properties on which the QSAR model has been trained and can be applied [56]. According to the prediction results, compounds 2a-f and E260 are in the applicability domain.

Most of the drugs used in medical practice are administered orally, which is associated with the convenience, cost-effectiveness, and safety of this administration method [57]. Lipinski's rule, also known as the rule of five, helps determine whether a chemical compound has properties that make it orally active in humans. This rule of thumb is based on the observation that most orally administered drugs are relatively small and moderately lipophilic molecules. The rule describes molecular properties important for a drug's pharmacokinetics in the human body, including its absorption, distribution, metabolism, and excretion [58]. Compounds 2a-f and E260 complied with Lipinski's rule of five (supporting information Table $\mathrm{S} 2)$ and, therefore, were predicted to be active by the oral route $[59,60]$. For compounds $2 \mathrm{a}-\mathrm{f}$ the probability was 0.5571-0.6286, and for E260, it was 0.6286 (supporting information Table S3).

Human intestinal absorption (HIA) is an important property for potential drug candidates. HIA is one of the key steps in the delivery of drugs to their targets. For all compounds studied, a high probability (for 2a-f - 0.9251-0.9404 and for E260 - 0.9948) was predicted to be absorbed in the human intestine (supporting information Table S3) [61,62].

The effectiveness of a drug depends on the degree of its binding to blood plasma proteins. The drugs are in the blood in two forms - bound and unbound. Depending on the affinity of a particular drug for plasma proteins, one part can go into a bound form, while the other part remains unbound. It is the unbound part of the drug that provides the therapeutic 
effect [63]. According to the prediction results, all compounds analyzed had a low affinity for blood plasma proteins; the bound fraction ( $\mathrm{f}_{\mathrm{b}}$ ) was within $0.9-1.2 \%$ (for $2 \mathrm{a}-\mathrm{f}$ ) and $0.9 \%$ for E260 (supporting information Table S3).

$\mathrm{P}$-glycoprotein $(\mathrm{P}-\mathrm{gp})$ is a transmembrane carrier protein belonging to the $\mathrm{ABC}$ family (ATP-binding cassette). This protein is actively involved in absorbing drugs from the intestine, metabolism, and transfer across biological barriers [64]. Concerning this transporter, all biologically active substances are conventionally divided into substrates and inhibitors. Usually, if the drug is a substrate, then it does not show inhibitory activity against P-gp, and vice versa. However, in some cases, the same substance can act both as a substrate and as an inhibitor, depending on its concentration [65]. Compounds 2a-f act as P-gp inhibitors with a probability of 0.6722-0.9014 [64,66], while the role of substrate for these compounds was not predicted. In turn, E260 can act both as an inhibitor (probability 0.6819) and as a substrate (probability 0.7474 ) (supporting information Table S3) [67]. The ability of compounds 2a-f to inhibit P-gp can interfere with other drugs' transport and, therefore, enhance their action. That is, compounds $2 \mathrm{a}-\mathrm{f}$ can be used in combination therapy, for example, with anticancer drugs [68].

The blood-brain barrier is a unique set of blood vessels that filters everything that enters and exits the brain. For most modern anticancer drugs, the blood-brain barrier is an insurmountable barrier, which greatly complicates the fight against tumor formations in the brain [69-71]. According to the prediction results, compounds $2 \mathrm{a}-\mathrm{f}$ could penetrate the bloodbrain barrier with a high probability (0.9742-0.9826). The ability to enter the brain was predicted for the E260 compound with a probability of 0.9951 (supporting information Table S3) [61].

The human cytochrome P450 (CYP) family includes 57 isozymes. These enzymes are involved in normal metabolism and thus, affect the pharmacokinetics of drugs. The different behavior of biologically active compounds related to these enzymes can lead to unwanted drugdrug interactions (DDIs). CYP isozymes metabolize approximately two-thirds of drugs in the human body. The most active role in this is played by five isozymes - 1A2, 2C9, 2C19, 2D6, and 3A4 [72]. All compounds analyzed can act as substrates for CYP3A4 with a low probability (for 2a-f - 0.5591-0.6515 and 0.6127 - for E260). The role of substrates CYP2C9 and CYP2D6 is not predicted for compounds 2a-f. E260 can be a CYP2D6 substrate with a probability of 0.5327. In turn, compounds 2a-f can inhibit CYP2C9 with a probability of 0.6648-0.8559, while E260 cannot. All analyzed compounds are most likely unable to inhibit CYP2D6. In the case of CYP3A4, only compounds $2 \mathrm{a}$ and $2 \mathrm{f}$ can act as potential inhibitors, with a probability of 0.6808 and 0.8827 , respectively. CYP2C19 inhibition is predicted only for compound 2e, probability 0.6347 . Besides, compounds 2e and E260 have a low probability of blocking CYP1A2 (supporting information Table S4) [73,74].

According to the results of the prediction of oral toxicity for rats, compounds $2 \mathrm{a}-\mathrm{f}$ were assigned to toxicity class III (lightly toxic substances); LD50 was in the range of 1406.1-2588.2 $\mathrm{mg} / \mathrm{kg}$. Significantly higher toxicity was predicted for E260; LD50 was $239.4 \mathrm{mg} / \mathrm{kg}$, which classified this drug as a moderately toxic substance (toxicity class II) (supporting information Table S5) [75].

The Human Ether-a-go-go-Related gene Potassium Channel (hERG, Kv11.1) [76] is the main anti-target in the heart. Drug interactions with this channel are undesirable and can lead to serious cardiac disorders, arrhythmias, and, in some cases, death [76]. According to the prediction results, all analyzed compounds are capable of blocking hERG [77,78]. For 
compounds 2a-f, the probability was $0.6297-0.8280$, and for E260, it was 0.8927 (supporting information Table S5).

Drug-induced liver injury (DILI) is usually caused by the blockage of transmembrane transporters in the liver responsible for the outflow of bile acids from hepatocytes. Accumulation of toxic salts of bile acids in the liver leads to cholestasis and liver damage. The primary role for the bile outflow from hepatocytes is played by the bile salt export pump (BSEP) $[79,80]$. According to the prediction results, compounds 2a-f (with a probability of 0.6528-0.9207) and E260 (with a probability of 0.9489) could block BSEP. Therefore, hepatotoxicity was predicted for them $[81,82]$ : for compounds $2 \mathrm{a}-\mathrm{f}$, the probability was 0.6500 0.8250, and for E260 - 0.5250 (supporting information Table S5).

\section{Conclusions}

Using molecular modeling methods, we have carried out a comparative assessment of the affinity of $N$-(5-morpholino-2-arylimidazo[2,1-b][1,3,4]thiadiazol-6-yl)carboxamides 2a-f and 6-(4-isopropylphenyl)-2-(4-((4-methylpiperazin-1-yl)methyl)piperidin-1-yl)imidazo[2,1$b][1,3,4]$ thiadiazole (E260) to Fer kinase. It has been shown that compounds 2a-f predominantly form stronger complexes with this enzyme than the reference drug E260.

In silico ADMET prediction of the properties of compounds 2a-f and E260 has been carried out. Comparative analysis of the obtained results has shown that compounds $2 \mathrm{a}-\mathrm{f}$ are not inferior to the reference drug - E260 in most parameters and even surpasses it. In this case, for compounds 2a-f, in contrast to E260, the role of a substrate for P-gp is not predicted but, on the contrary, an inhibitory activity is predicted towards this carrier. This should control the concentration of compounds $2 \mathrm{a}-\mathrm{f}$ in cancer cells within the therapeutically effective range and use these compounds in combination therapy with other anticancer drugs. Also, compounds 2a-f are predicted to have approximately 6-10 times lower acute toxicity in rats than for E260.

All considered $\quad N$-(5-morpholino-2-arylimidazo[2,1-b][1,3,4]thiadiazol-6yl)carboxamides (2a-f) have shown promising results under in silico experimental conditions and can be recommended for further studies on tumor cell cultures.

\section{Funding}

This research received no external funding.

\section{Acknowledgments}

This research has no acknowledgments.

\section{Conflicts of Interest}

The authors declare no conflict of interest.

\section{References}

1. Khazi, I.A.M.; Gadad, A.K.; Lamani, R.S.; Bhongade, B.A. Chemistry of imidazo[2,1-b][1,3,4]thiadiazoles. Tetrahedron 2011, 67, 3289-3316, https://doi.org/10.1016/j.tet.2011.03.027.

2. Lata; Kushwaha, K.; Gupta, A.; Meena, D.; Verma, A. Biological activities of imidazo[2,1b][1,3,4]thiadiazole derivatives: a review. Heterocyclic Letters 2015, 5, 489-509. 
3. Bhongade, B.A.; Talath, S.; Gadad, R.A.; Gadad, A.K. Biological activities of imidazo[2,1b][1,3,4]thiadiazole derivatives: A review. Journal of Saudi Chemical Society 2016, 20, S463-S475, https://doi.org/10.1016/j.jscs.2013.01.010.

4. Er, M.; Ahmadov, F.; Karakurt, T.; Direkel, Ş.; Tahtaci, H. A Novel Class Substituted Imidazo[2,1b][1,3,4]thiadiazole Derivatives: Synthesis, Characterization, In Vitro Biological Activity, and Potential Inhibitors Design Studies. ChemistrySelect 2019, 4, 14281-14290, http://dx.doi.org/10.1002/slct.201903886.

5. Er, M.; Özer, A.; Direkel, Ş.; Karakurt, T.; Tahtaci, H. Novel substituted benzothiazole and Imidazo[2,1b][1,3,4]Thiadiazole derivatives: Synthesis, characterization, molecular docking study, and investigation of their in vitro antileishmanial and antibacterial activities. J. Mol. Struct. 2019, 1194, 284-296, https://doi.org/10.1016/j.molstruc.2019.05.104.

6. Taflan, E.; Bayrak, H.; Er, M.; Alpay Karaoğlu, Ş.; Bozdeveci, A. Novel imidazo[2,1-b][1,3,4]thiadiazole (ITD) hybrid compounds: Design, synthesis, efficient antibacterial activity and antioxidant effects. Bioorg. Chem. 2019, 89, 102998, https://doi.org/10.1016/j.bioorg.2019.102998.

7. El-Gohary, N.S.; Shaaban, M.I. Synthesis, antimicrobial, antiquorum-sensing, antitumor and cytotoxic activities of new series of fused [1,3,4]thiadiazoles. Eur. J. Med. Chem. 2013, 63, 185-195, https://doi.org/10.1016/j.ejmech.2013.02.010.

8. El-Gohary, N.S.; Shaaban, M.I. Antimicrobial and Antiquorum-Sensing Studies. Part 3: Synthesis and Biological Evaluation of New Series of [1,3,4]Thiadiazoles and Fused [1,3,4]Thiadiazoles. Arch. Pharm. 2015, 348, 283-297, https://doi.org/10.1002/ardp.201400381.

9. Cascioferro, S.; Parrino, B.; Petri, G.L.; Cusimano, M.G.; Schillaci, D.; Di Sarno, V.; Musella, S.; Giovannetti, E.; Cirrincione, G.; Diana, P. 2,6-Disubstituted imidazo[2,1-b][1,3,4]thiadiazole derivatives as potent staphylococcal biofilm inhibitors. Eur. J. Med. Chem. 2019, 167, 200-210, https://doi.org/10.1016/j.ejmech.2019.02.007.

10. Er, M.; Tahtaci, H.; Karakurt, T.; Onaran, A. Novel Substituted Imidazo[2,1-b][1,3,4]Thiadiazole Derivatives: Synthesis, Characterization, Molecular Docking Study, and Investigation of Their In Vitro Antifungal Activities. J. Heterocycl. Chem. 2019, 56, 2555-2570, https://doi.org/10.1002/jhet.3653.

11. Syed, M.A.; Reddy, Y.R.P.; Chandrasekhar, K.B. Design, one pot synthesis and biological evaluation of imidazo [2, 1-b][1, 3, 4]-thiadiazole derivatives for their antitubercular and antifungal activity. Journal of Applied Pharmaceutical Science 2018, 8, 021-027, http://dx.doi.org/10.7324/JAPS.2018.8704.

12. Patel, H.M.; Noolvi, M.N.; Sethi, N.S.; Gadad, A.K.; Cameotra, S.S. Synthesis and antitubercular evaluation of imidazo[2,1-b][1,3,4]thiadiazole derivatives. Arabian Journal of Chemistry 2017, 10, S996-S1002, http://dx.doi.org/10.1016/j.arabjc.2013.01.001.

13. Makwane, S.; Dua, R. Synthesis and Antitubercular Acitivity of New Imidazo[2,1-B][1,3,4]ThiadiazolePhenothiazine Derivatives. Arch. Org. Inorg. Chem. Sci. 2018, 3, 391-397, http://dx.doi.org/10.32474/AOICS.2018.03.000169.

14. Fascio, M.L.; Sepúlveda, C.S.; Damonte, E.B.; D'Accorso, N.B. Synthesis and antiviral activity of some imidazo[1,2-b][1,3,4]thiadiazole carbohydrate derivatives. Carbohydr. Res. 2019, 480, 61-66, https://doi.org/10.1016/j.carres.2019.05.003.

15. Cristina, A.; Leonte, D.; Vlase, L.; Bencze, L.C.; Imre, S.; Marc, G.; Apan, B.; Mogoșan, C.; Zaharia, V. Heterocycles 48. Synthesis, Characterization and Biological Evaluation of Imidazo[2,1-b][1,3,4]Thiadiazole Derivatives as Anti-Inflammatory Agents. Molecules 2018, 23, https://doi.org/10.3390/molecules23102425.

16. Li, Z.; Hu, L.; Wang, X.; Zhou, Z.; Deng, L.; Xu, Y.; Zhang, L. Design, synthesis, and biological evaluation of novel dual FFA1 (GPR40)/PPAR $\delta$ agonists as potential anti-diabetic agents. Bioorg. Chem. 2019, 92, 103254, https://doi.org/10.1016/j.bioorg.2019.103254.

17. Miller, M.M.; Banville, J.; Friends, T.J.; Gagnon, M.; Hangeland, J.J.; Lavallée, J.-F.; Martel, A.; O’Grady, H.; Rémillard, R.; Ruediger, E.; Tremblay, F.; Posy, S.L.; Allegretto, N.J.; Guarino, V.R.; Harden, D.G.; Harper, T.W.; Hartl, K.; Josephs, J.; Malmstrom, S.; Watson, C.; Yang, Y.; Zhang, G.; Wong, P.; Yang, J.; Bouvier, M.; Seiffert, D.A.; Wexler, R.R.; Lawrence, R.M.; Priestley, E.S.; Marinier, A. Discovery of Potent Protease-Activated Receptor 4 Antagonists with in Vivo Antithrombotic Efficacy. J. Med. Chem. 2019, 62, 7400-7416, http://dx.doi.org/10.1021/acs.jmedchem.9b00186.

18. Sara, A.; Omidreza, F.; Aida, I.; Afsaneh, Z.; Mahsima, K.; Mohammad, M.; Najmeh, E. Synthesis and In Vitro Biological Activity Evaluation of Novel Imidazo [2,1-B][1,3,4] Thiadiazole as Anti-Alzheimer Agents. $\begin{array}{lllllll}\text { Letters in Drug Design \& } & \text { Discovery } & \text { 2020, } & \text { 17, }\end{array}$ http://dx.doi.org/10.2174/1570180816666181108115510. 
19. Sbenati, R.M.; Semreen, M.H.; Semreen, A.M.; Shehata, M.K.; Alsaghir, F.M.; El-Gamal, M.I. Evaluation of imidazo[2,1-b]thiazole-based anticancer agents in one decade (2011-2020): Current status and future prospects. Biorg. Med. Chem. 2021, 29, 115897, https://doi.org/10.1016/j.bmc.2020.115897.

20. Chakrapani, B.; Ramesh, V.; Pourna Chander Rao, G.; Ramachandran, D.; Madhukar Reddy, T.; Kalyan Chakravarthy, A.; Sridhar, G. Synthesis and Anticancer Evaluation of 1,2,4-Oxadiazole Linked Imidazothiadiazole Derivatives. Russ. J. Gen. Chem. 2018, 88, 1020-1024, https://doi.org/10.1134/S1070363218050304.

21. Cascioferro, S.; Petri, G.L.; Parrino, B.; Carbone, D.; Funel, N.; Bergonzini, C.; Mantini, G.; Dekker, H.; Geerke, D.; Peters, G.J.; Cirrincione, G.; Giovannetti, E.; Diana, P. Imidazo[2,1-b] [1,3,4]thiadiazoles with antiproliferative activity against primary and gemcitabine-resistant pancreatic cancer cells. Eur. J. Med. Chem. 2020, 189, 112088, https://doi.org/10.1016/j.ejmech.2020.112088.

22. Narasimha Rao, M.P.; Nagaraju, B.; Kovvuri, J.; Polepalli, S.; Alavala, S.; Vishnuvardhan, M.V.P.S.; Swapna, P.; Nimbarte, V.D.; Lakshmi, J.K.; Jain, N.; Kamal, A. Synthesis of imidazo-thiadiazole linked indolinone conjugates and evaluated their microtubule network disrupting and apoptosis inducing ability. Bioorg. Chem. 2018, 76, 420-436, https://doi.org/10.1016/j.bioorg.2017.11.021.

23. Reddy, A.G.; Sireesha, R.; Babu, V.H.; Rao, Y.J.P.; Susithra, E.; Rao, M.V.B. Design, synthesis, antiproliferative and molecular docking studies of quinazolinone-imidazo[2,1-b][1,3,4]thiadiazole hybrid derivatives. Chemical Data Collections 2021, 31, 100614, https://doi.org/10.1016/j.cdc.2020.100614.

24. Li Petri, G.; Cascioferro, S.; El Hassouni, B.; Carbone, D.; Parrino, B.; Cirrincione, G.; Peters, G.J.; Diana, P.; Giovannetti, E. Biological Evaluation of the Antiproliferative and Anti-migratory Activity of a Series of 3-(6-Phenylimidazo[2,1-b][1,3,4]thiadiazol-2-yl)-1H-indole Derivatives Against Pancreatic Cancer Cells. Anticancer Res. 2019, 39, 3615, https://doi.org/10.21873/anticanres.13509.

25. Li Petri, G.; Pecoraro, C.; Randazzo, O.; Zoppi, S.; Cascioferro, S.M.; Parrino, B.; Carbone, D.; El Hassouni, B.; Cavazzoni, A.; Zaffaroni, N.; Cirrincione, G.; Diana, P.; Peters, G.J.; Giovannetti, E. New Imidazo[2,1b][1,3,4]Thiadiazole Derivatives Inhibit FAK Phosphorylation and Potentiate the Antiproliferative Effects of Gemcitabine Through Modulation of the Human Equilibrative Nucleoside Transporter-1 in Peritoneal Mesothelioma. Anticancer Res. 2020, 40, 4913, https://doi.org/10.21873/anticanres.14494.

26. Potikha, L.M.; Brovarets, V.S. Synthesis of imidazo[2,1-b][1,3]thiazoles - potential anticancer agents derived from $\gamma$-bromodipnones. Chemistry of Heterocyclic Compounds 2020, 56, 1073-1077, https://doi.org/10.1007/s10593-020-02776-4.

27. Sridhar, G.; Palle, S.; Vantikommu, J.; Gangarapu, K. Design, synthesis, and biological evaluation of amide derivatives of imidazo[2,1-b][1,3,4]thiadiazole as anticancer agents. Synth. Commun. 2020, 50, 3221-3233, https://doi.org/10.1080/00397911.2020.1797814.

28. Choodamani, B.; Cano Hernandez, K.G.; Kumar, S.; Tony, A.M.; Schiaffino Bustamante, A.Y.; Aguilera, R.J.; Schols, D.; Gopi Mohan, C.; Karki, S.S. Synthesis, Molecular Docking and Preliminary Antileukemic Activity of 4-Methoxybenzyl Derivatives Bearing Imidazo[2,1-b][1,3,4]thiadiazole. Chem. Biodivers. 2021, 18, e2000800, https://doi.org/10.1002/cbdv.202000800.

29. Elkis, Y.; Cohen, M.; Yaffe, E.; Satmary-Tusk, S.; Feldman, T.; Hikri, E.; Nyska, A.; Feiglin, A.; Ofran, Y.; Shpungin, S.; Nir, U. A novel Fer/FerT targeting compound selectively evokes metabolic stress and necrotic death in malignant cells. Nature Communications 2017, 8, 940, https://doi.org/10.1038/s41467-017-00832w.

30. Hikri, E.; Shpungin, S.; Nir, U. Hsp90 and a tyrosine embedded in the Hsp90 recognition loop are required for the Fer tyrosine kinase activity. Cell. Signal. 2009, 21, 588-596, https://doi.org/10.1016/j.cellsig.2008.12.011.

31. Yaffe, E.; Hikri, E.; Elkis, Y.; Cohen, O.; Segal, A.; Makovski, A.; Varvak, A.; Shpungin, S.; Nir, U. Oncogenic Properties of a Spermatogenic Meiotic Variant of Fer Kinase Expressed in Somatic Cells. Cancer Res. 2014, 74, 6474, https://doi.org/10.1158/0008-5472.CAN-14-0058.

32. Chernous, S.Y.; Okhtina, O.V.; Kiselev, V.V.; Kharchenko, A.V. New approach to the synthesis of imidazo [2, 1-b][1, 3, 4] thiadiazoles derivatives. Vopr. Khim. Khim. Tekhnol. 2010, 30-33.

33. Zadorozhnii, P.V.; Kiselev, V.V.; Kharchenko, A.V. Synthesis of Nitrogen-Containing Heterocycles Based on N-(Isothiocyanatoalkyl)carboxamides. In Modern Directions in Chemistry, Biology, Pharmacy and Biotechnology. Novikov, V., Ed.; Lviv Polytechnic Publishing House: Lviv, Ukraine, 2015, pp. $212-219$.

34. Zadorozhnii, P.; Kiselev, V.; Kharchenko, A.; Krvavych, A.; Novikov, V. The molecular structure N-\{2, 2 , 2-trichloro-1-[(5-phenyl-1, 3, 4-thiadiazol-2-yl) amino] ethyl \} acet-and Thioacetamide. Research Journal of Pharmaceutical, Biological and Chemical Sciences 2015, 6, 689-695. 
35. Fan, J.; Fu, A.; Zhang, L. Progress in molecular docking. Quantitative Biology 2019, 7, 83-89, https://doi.org/10.1007/s40484-019-0172-y.

36. Pinzi, L.; Rastelli, G. Molecular Docking: Shifting Paradigms in Drug Discovery. Int. J. Mol. Sci. 2019, 20, https://doi.org/10.3390/ijms20184331.

37. Waterhouse, A.; Bertoni, M.; Bienert, S.; Studer, G.; Tauriello, G.; Gumienny, R.; Heer, F.T.; de Beer, T.A P.; Rempfer, C.; Bordoli, L.; Lepore, R.; Schwede, T. SWISS-MODEL: homology modelling of protein structures and complexes. Nucleic Acids Res. 2018, 46, W296-W303, https://doi.org/10.1093/nar/gky427.

38. The UniProt, C. UniProt: a worldwide hub of protein knowledge. Nucleic Acids Res. 2019, 47, D506-D515, https://doi.org/10.1093/nar/gky1049.

39. Taniguchi, T.; Inagaki, H.; Baba, D.; Yasumatsu, I.; Toyota, A.; Kaneta, Y.; Kiga, M.; Iimura, S.; Odagiri, T.; Shibata, Y.; Ueda, K.; Seo, M.; Shimizu, H.; Imaoka, T.; Nakayama, K. Discovery of Novel Pyridopyridazinone Derivatives as FER Tyrosine Kinase Inhibitors with Antitumor Activity. ACS Med. Chem. Lett. 2019, 10, 737-742, https://doi.org/10.1021/acsmedchemlett.8b00631.

40. Krieger, E.; Joo, K.; Lee, J.; Lee, J.; Raman, S.; Thompson, J.; Tyka, M.; Baker, D.; Karplus, K. Improving physical realism, stereochemistry, and side-chain accuracy in homology modeling: Four approaches that performed well in CASP8. Proteins: Structure, Function, and Bioinformatics 2009, 77, 114-122, https://doi.org/10.1002/prot.22570.

41. Thiel, W. Semiempirical quantum-chemical methods. WIREs Computational Molecular Science 2014, 4, 145-157, https://doi.org/10.1002/wcms.1161.

42. Thompson, M.A.; Zerner, M.C. A theoretical examination of the electronic structure and spectroscopy of the photosynthetic reaction center from Rhodopseudomonas viridis. J. Am. Chem. Soc. 1991, 113, 8210-8215, https://doi.org/10.1021/ja00022a003.

43. Thompson, M.A.; Glendening, E.D.; Feller, D. The Nature of $\mathrm{K}+/$ Crown Ether Interactions: A Hybrid Quantum Mechanical-Molecular Mechanical Study. The Journal of Physical Chemistry 1994, 98, 1046510476, https://doi.org/10.1021/j100092a015.

44. Thompson, M.A.; Schenter, G.K. Excited States of the Bacteriochlorophyll b Dimer of Rhodopseudomonas viridis: A QM/MM Study of the Photosynthetic Reaction Center That Includes MM Polarization. The Journal of Physical Chemistry 1995, 99, 6374-6386, https://doi.org/10.1021/j100017a017.

45. Thompson, M.A. QM/MMpol: A Consistent Model for Solute/Solvent Polarization. Application to the Aqueous Solvation and Spectroscopy of Formaldehyde, Acetaldehyde, and Acetone. The Journal of Physical Chemistry 1996, 100, 14492-14507, https://doi.org/10.1021/jp960690m.

46. Thompson, M. ArgusLab 4.0.1. Planaria software LLC, Seattle, Wash, USA. 2004. Available online: http://www.arguslab.com.

47. Zadorozhnii, P.V.; Kiselev, V.V.; Teslenko, N.O.; Kharchenko, A.V.; Pokotylo, I.O.; Okhtina, O.V.; Kryshchyk, O.V. In silico Prediction and Molecular Docking Studies of $\mathrm{N}$-amidoalkylated Derivatives of 1,3,4-oxadiazole as COX-1 and COX-2 Potential Inhibitors. Research Journal of Pharmacy and Technology 2017, 10, 3957-3963, https://doi.org/10.5958/0974-360X.2017.00718.1.

48. Zadorozhnii, P.V.; Pokotylo, I.O.; Kiselev, V.V.; Okhtina, O.V.; Kharchenko, A.V. Molecular Docking Studies of $N$-(((5-Aryl-1,3,4-oxadiazol-2-yl)amino)methyl)- and $N$-(2,2,2-Trichloro-1-((5-aryl-1,3,4oxadiazol-2-yl)amino)ethyl)carboxamides as Potential Inhibitors of GSK-3ß. Research Journal of Pharmacy and Technology 2019, 12, 523-530, https://doi.org/10.5958/0974-360X.2019.00092.1.

49. Zadorozhnii, P.V.; Kiselev, V.V.; Titova, A.E.; Kharchenko, A.V.; Pokotylo, I.O.; Okhtina, O.V. Molecular Docking Studies of N-5-Aryl-1,3,4-oxadiazolo-2,2-dichloroacetamidines as Inhibitors of Enoyl-ACP Reductase Mycobacterium tuberculosis. Research Journal of Pharmacy and Technology 2017, 10, 1091, https://doi.org/10.5958/0974-360X.2019.00092.1.

50. Zadorozhnii, P.V.; Pokotylo, I.O.; Kiselev, V.V.; Okhtina, O.V.; Kharchenko, A.V. Molecular docking studies of salubrinal and its analogs as inhibitors of the GADD34:PP1 enzyme. ADMET and DMPK 2019, 7 , 140-150, https://doi.org/10.5599/admet.632.

51. Trott, O.; Olson, A.J. AutoDock Vina: Improving the speed and accuracy of docking with a new scoring function, efficient optimization, and multithreading. J. Comput. Chem. 2010, 31, 455-461, https://doi.org/10.1002/jcc.21334.

52. O'Boyle, N.M.; Banck, M.; James, C.A.; Morley, C.; Vandermeersch, T.; Hutchison, G.R. Open Babel: An open chemical toolbox. J. Cheminform. 2011, 3, 33, https://doi.org/10.1186/1758-2946-3-33.

53. DeLano, W.L. The PyMOL Molecular Graphics System, DeLano Scientific: Palo Alto, CA. 2003. Available online: http://www.pymol.org. 
54. Yang, H.; Lou, C.; Sun, L.; Li, J.; Cai, Y.; Wang, Z.; Li, W.; Liu, G.; Tang, Y. admetSAR 2.0: web-service for prediction and optimization of chemical ADMET properties. Bioinformatics 2019, 35, 1067-1069, https://doi.org/10.1093/bioinformatics/bty707.

55. Cheng, F.; Li, W.; Zhou, Y.; Shen, J.; Wu, Z.; Liu, G.; Lee, P.W.; Tang, Y. admetSAR: A Comprehensive Source and Free Tool for Assessment of Chemical ADMET Properties. J. Chem. Inf. Model. 2012, 52, 30993105, https://doi.org/10.1021/ci300367a.

56. Muratov, E.N.; Bajorath, J.; Sheridan, R.P.; Tetko, I.V.; Filimonov, D.; Poroikov, V.; Oprea, T.I.; Baskin, I.I.; Varnek, A.; Roitberg, A.; Isayev, O.; Curtalolo, S.; Fourches, D.; Cohen, Y.; Aspuru-Guzik, A.; Winkler, D.A.; Agrafiotis, D.; Cherkasov, A.; Tropsha, A. QSAR without borders. Chem. Soc. Rev. 2020, 49, 35253564, https://doi.org/10.1039/d0cs00098a.

57. Ruiz, M.E.; Scioli Montoto, S. Routes of Drug Administration. In ADME Processes in Pharmaceutical Sciences: Dosage, Design, and Pharmacotherapy Success, Talevi, A., Quiroga, P.A.M., Eds. Springer International Publishing: Cham, 2018; 10, pp. 97-133, https://doi.org/10.1007/978-3-319-99593-9_6.

58. Lipinski, C.A.; Lombardo, F.; Dominy, B.W.; Feeney, P.J. Experimental and computational approaches to estimate solubility and permeability in drug discovery and development settings. Adv. Drug Del. Rev. 2001, 46, 3-26, https://doi.org/10.1016/S0169-409X(00)00129-0.

59. Tian, S.; Li, Y.; Wang, J.; Zhang, J.; Hou, T. ADME Evaluation in Drug Discovery. 9. Prediction of Oral Bioavailability in Humans Based on Molecular Properties and Structural Fingerprints. Mol. Pharm. 2011, 8, 841-851, https://doi.org/10.1021/mp100444g.

60. Ma, C.-Y.; Yang, S.-Y.; Zhang, H.; Xiang, M.-L.; Huang, Q.; Wei, Y.-Q. Prediction models of human plasma protein binding rate and oral bioavailability derived by using GA-CG-SVM method. J. Pharm. Biomed. Anal. 2008, 47, 677-682, https://doi.org/10.1016/j.jpba.2008.03.023.

61. Shen, J.; Cheng, F.; Xu, Y.; Li, W.; Tang, Y. Estimation of ADME Properties with Substructure Pattern Recognition. J. Chem. Inf. Model. 2010, 50, 1034-1041, https://doi.org/10.1021/ci100104j.

62. Wang, N.-N.; Huang, C.; Dong, J.; Yao, Z.-J.; Zhu, M.-F.; Deng, Z.-K.; Lv, B.; Lu, A.-P.; Chen, A.F.; Cao, D.-S. Predicting human intestinal absorption with modified random forest approach: a comprehensive evaluation of molecular representation, unbalanced data, and applicability domain issues. RSC Advances 2017, 7, 19007-19018, https://doi.org/10.1039/C6RA28442F.

63. Sun, L.; Yang, H.; Li, J.; Wang, T.; Li, W.; Liu, G.; Tang, Y. In Silico Prediction of Compounds Binding to Human Plasma Proteins by QSAR Models. ChemMedChem 2018, 13, 572-581, https://doi.org/10.1002/cmdc.201700582.

64. Broccatelli, F.; Carosati, E.; Neri, A.; Frosini, M.; Goracci, L.; Oprea, T.I.; Cruciani, G. A Novel Approach for Predicting P-Glycoprotein (ABCB1) Inhibition Using Molecular Interaction Fields. J. Med. Chem. 2011, 54, 1740-1751, https://doi.org/10.1021/jm101421d.

65. Didziapetris, R.; Japertas, P.; Avdeef, A.; Petrauskas, A. Classification Analysis of P-Glycoprotein Substrate Specificity. J. Drug Targeting 2003, 11, 391-406, https://doi.org/10.1080/10611860310001648248.

66. Chen, L.; Li, Y.; Zhao, Q.; Peng, H.; Hou, T. ADME Evaluation in Drug Discovery. 10. Predictions of PGlycoprotein Inhibitors Using Recursive Partitioning and Naive Bayesian Classification Techniques. Mol. Pharm. 2011, 8, 889-900, https://doi.org/10.1021/mp100465q.

67. Wang, Z.; Chen, Y.; Liang, H.; Bender, A.; Glen, R.C.; Yan, A. P-glycoprotein Substrate Models Using Support Vector Machines Based on a Comprehensive Data set. J. Chem. Inf. Model. 2011, 51, 1447-1456, https://doi.org/10.1021/ci2001583.

68. Prachayasittikul, V.; Prachayasittikul, V. P-glycoprotein transporter in drug development. EXCLI Journal 2016, 15, 113, https://doi.org/10.17179/excli2015-768.

69. Angeli, E.; Nguyen, T.T.; Janin, A.; Bousquet, G. How to Make Anticancer Drugs Cross the Blood-Brain Barrier to Treat Brain Metastases. Int. J. Mol. Sci. 2020, 21, https://doi.org/10.3390/ijms21010022.

70. Arvanitis, C.D.; Ferraro, G.B.; Jain, R.K. The blood-brain barrier and blood-tumour barrier in brain tumours and metastases. Nature Reviews Cancer 2020, 20, 26-41, https://doi.org/10.1038/s41568-019-0205-x.

71. Bhowmik, A.; Khan, R.; Ghosh, M.K. Blood Brain Barrier: A Challenge for Effectual Therapy of Brain Tumors. BioMed Research International 2015, 2015, 320941, https://doi.org/10.1155/2015/320941.

72. Veith, H.; Southall, N.; Huang, R.; James, T.; Fayne, D.; Artemenko, N.; Shen, M.; Inglese, J.; Austin, C.P.; Lloyd, D.G.; Auld, D.S. Comprehensive characterization of cytochrome P450 isozyme selectivity across chemical libraries. Nat. Biotechnol. 2009, 27, 1050-1055, https://doi.org/10.1038/nbt.1581. 
73. Cheng, F.; Yu, Y.; Shen, J.; Yang, L.; Li, W.; Liu, G.; Lee, P.W.; Tang, Y. Classification of Cytochrome P450 Inhibitors and Noninhibitors Using Combined Classifiers. J. Chem. Inf. Model. 2011, 51, 996-1011, https://doi.org/10.1021/ci200028n.

74. Carbon-Mangels, M.; Hutter, M.C. Selecting Relevant Descriptors for Classification by Bayesian Estimates: A Comparison with Decision Trees and Support Vector Machines Approaches for Disparate Data Sets. Mol. Inform. 2011, 30, 885-895, https://doi.org/10.1002/minf.201100069.

75. Zhu, H.; Martin, T.M.; Ye, L.; Sedykh, A.; Young, D.M.; Tropsha, A. Quantitative Structure-Activity Relationship Modeling of Rat Acute Toxicity by Oral Exposure. Chem. Res. Toxicol. 2009, 22, 1913-1921, https://doi.org/10.1021/tx900189p.

76. Villoutreix, B.O.; Taboureau, O. Computational investigations of hERG channel blockers: New insights and current predictive models. Adv. Drug Del. Rev. 2015, 86, 72-82, https://doi.org/10.1016/j.addr.2015.03.003.

77. Marchese Robinson, R.L.; Glen, R.C.; Mitchell, J.B.O. Development and Comparison of hERG Blocker Classifiers: Assessment on Different Datasets Yields Markedly Different Results. Mol. Inform. 2011, 30, 443458, https://doi.org/10.1002/minf.201000159.

78. Wang, S.; Li, Y.; Wang, J.; Chen, L.; Zhang, L.; Yu, H.; Hou, T. ADMET Evaluation in Drug Discovery. 12. Development of Binary Classification Models for Prediction of hERG Potassium Channel Blockage. Mol. Pharm. 2012, 9, 996-1010, https://doi.org/10.1021/mp300023x.

79. Jackson, J.P.; Freeman, K.M.; St. Claire, R.L.; Black, C.B.; Brouwer, K.R. Cholestatic Drug Induced Liver Injury: A Function of Bile Salt Export Pump Inhibition and Farnesoid X Receptor Antagonism. Applied In Vitro Toxicology 2018, 4, 265-279, http://doi.org/10.1089/aivt.2018.0011.

80. Kolarić, T.O.; Ninčević, V.; Smolić, R.; Smolić, M.; Wu, G.Y. Mechanisms of hepatic cholestatic drug injury. Journal of Clinical and Translational Hepatology 2019, 7, 86, http://doi.org/10.14218/JCTH.2018.00042.

81. Fourches, D.; Barnes, J.C.; Day, N.C.; Bradley, P.; Reed, J.Z.; Tropsha, A. Cheminformatics Analysis of Assertions Mined from Literature That Describe Drug-Induced Liver Injury in Different Species. Chem. Res. Toxicol. 2010, 23, 171-183, http://doi.org/10.1021/tx900326k.

82. Rodgers, A.D.; Zhu, H.; Fourches, D.; Rusyn, I.; Tropsha, A. Modeling Liver-Related Adverse Effects of Drugs Using kNearest Neighbor Quantitative Structure-Activity Relationship Method. Chem. Res. Toxicol. 2010, 23, 724-732, https://doi.org/10.1021/tx900451r. 


\section{Supplementary files}

a)

MGFGSDLKNSHEAVLKLQDWELRLLETVKKFMALRIKSDKEYASTLQNLCNQVDKESTVQ MNYVSNVSKSWLLMIQQTEQLSRIMKTHAEDLNSGPLHRLTMMIKDKQQVKKSYIGVHQQ LHNOYVLALKGAOL HONOYYDITLPLLLDSLOKMOEEMIKALKGI DEYSOITSIVTEEI VNVHKE IQMSVEQIDPSTEYNNETDVHRTTAAKEOETE FDTSLI ENENL TAESLQVML KTI AETMQTOML DNKEEAVLELEKRTEESSETCEKKSDIVILISOKQAI EELKOSVOOLRCTEAKFSAOKELLEOKVOENDGKEPPPVVNYEEDARSVTSMERKERLSK FESIRHSIAGI IRSPKSALGSSALSDMIS ISEKPLAEQDWYHGA I PRIEAQELLKKQGDF KSGVVLLNPI PKDKKWI LSHEDVI LGELLGKGNFGEVYKGTLKDKTSVAVKTCKEDLPQE LKIKF LQEAKI LKQYDH PNIVKLIGVCTQRQPVY I IMELVSGGDFLTFLRRKKDELKLKQ LVKF SLDAAAMLYLESKNCIHRDLAARNCLVGENNVLKISDFGMSRQEDGGVYSSSGLK UTYTMTNQAREQVERG

\section{Tyrosine-protein kinase Fer [Homo sapiens]} UniProt ID P16591 b)

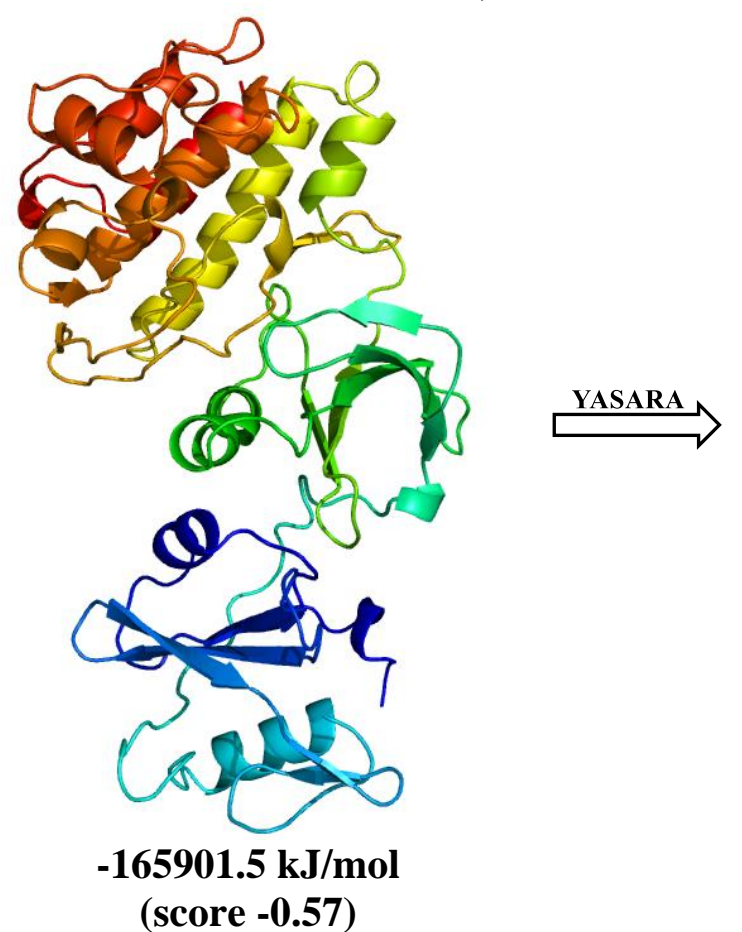

c)

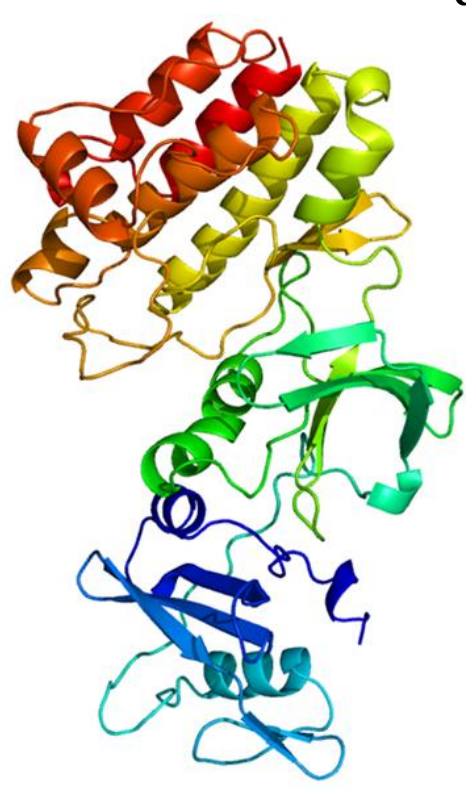

$-215245.1 \mathrm{~kJ} / \mathrm{mol}$ (score 0.24)

Figure S1. Algorithm for creating a model of the Fer kinase: a) amino acid sequence of Fer in the FASTA format; b) homology model based on the crystal structure of human tyrosine-protein kinase Fes/Fps (PDB ID: 6JMF); c) a model after optimization using the YASARA online server. 


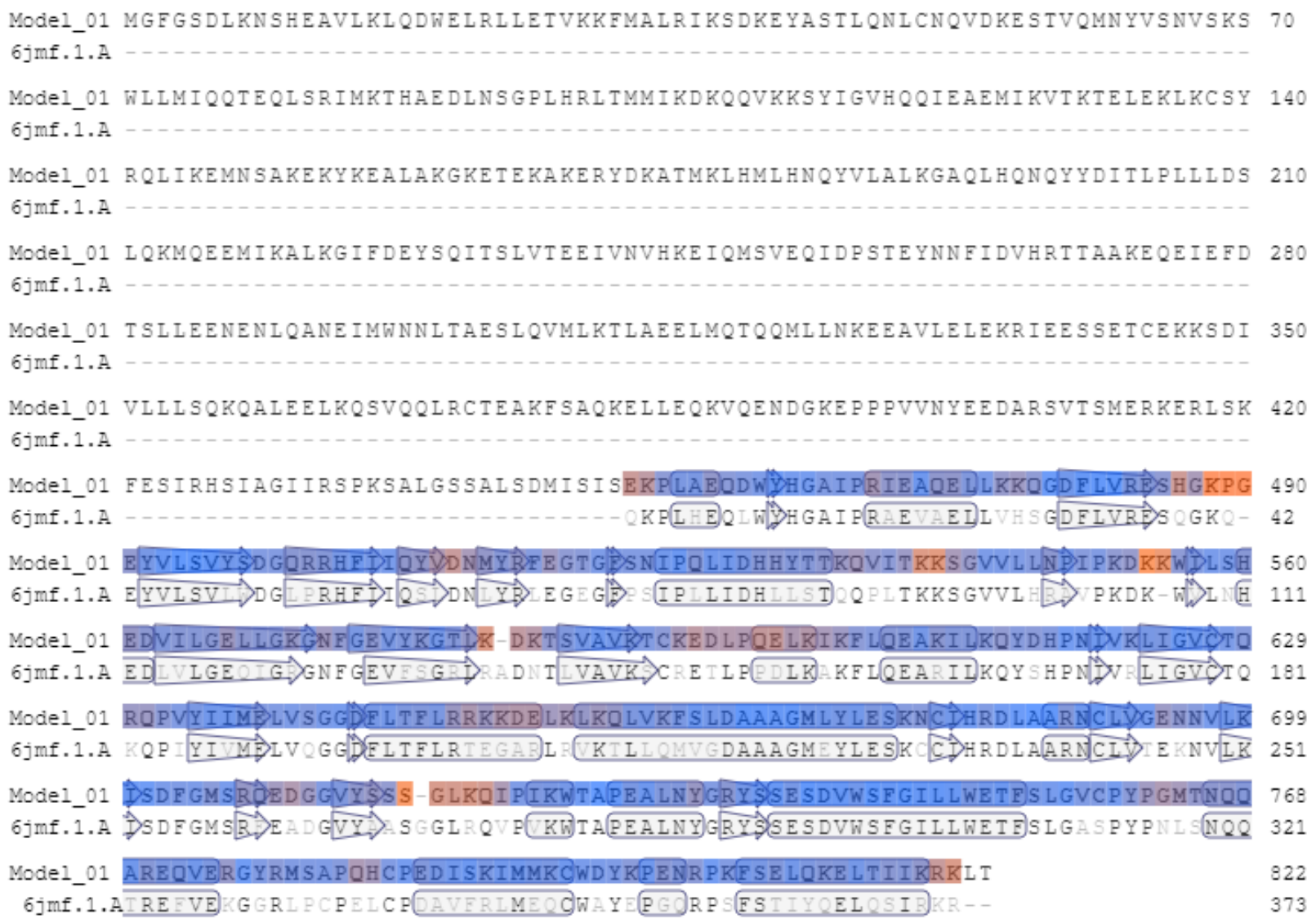

Figure S2. Alignment of human tyrosine-protein kinase Fer sequences with the structure of human tyrosine-protein kinase Fes/Fps (PDB ID: 6JMF). The sequence identity was $67.30 \%$. 


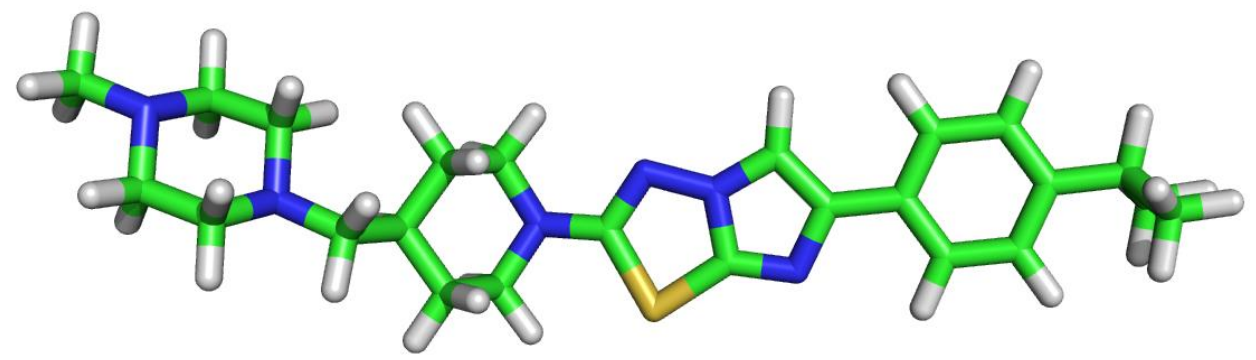

E260 $\Delta \mathrm{G}=-104383.2 \mathrm{kcal} / \mathrm{mol}$

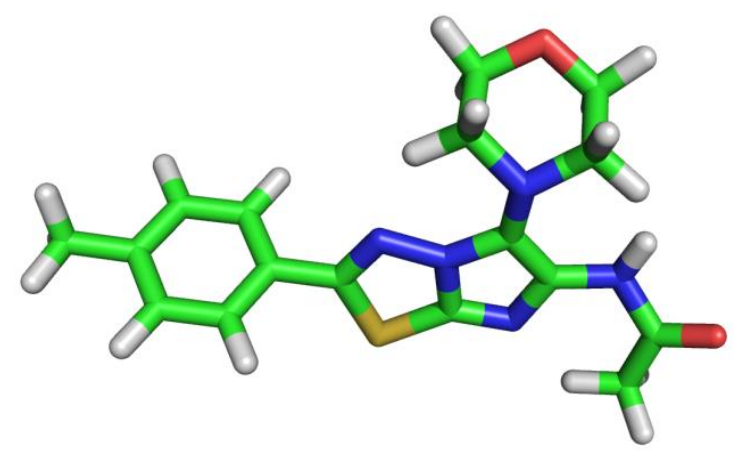

2a $\Delta \mathrm{G}=-89694.5 \mathrm{kcal} / \mathrm{mol}$

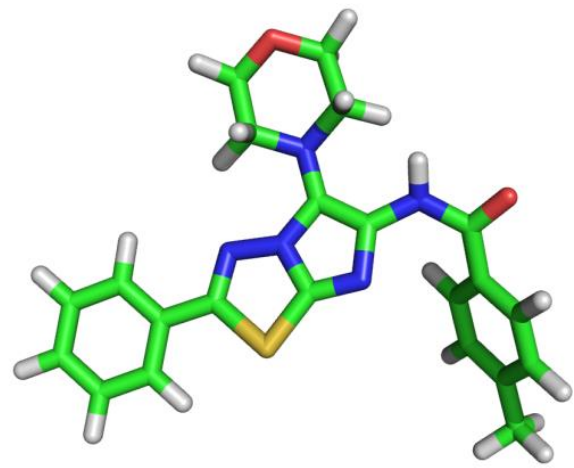

2c $\Delta \mathrm{G}=-104043.5 \mathrm{kcal} / \mathrm{mol}$

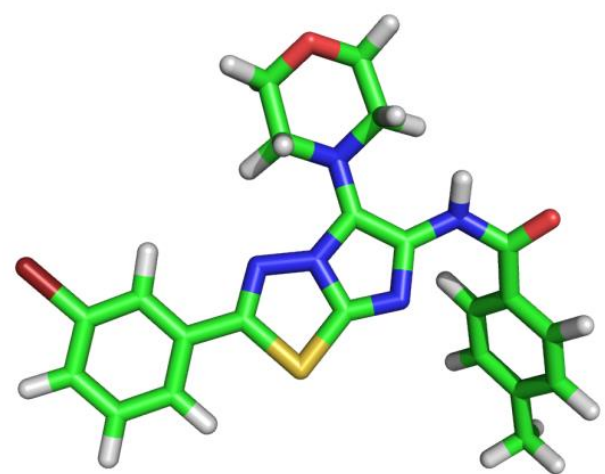

2e $\Delta \mathrm{G}=-111838.8 \mathrm{kcal} / \mathrm{mol}$

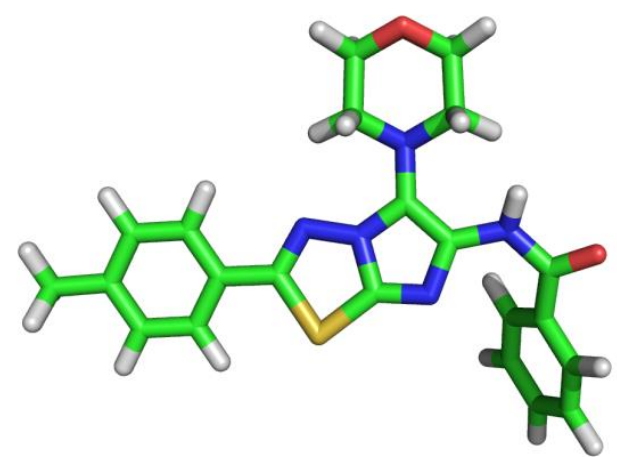

2b $\Delta \mathrm{G}=-104043.8 \mathrm{kcal} / \mathrm{mol}$

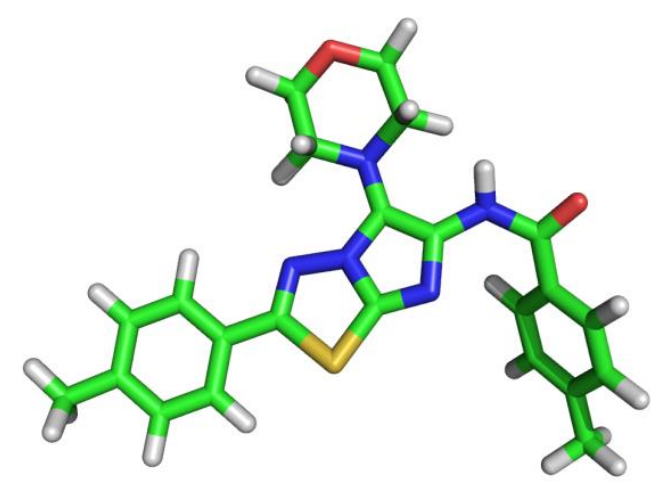

2d $\Delta \mathrm{G}=-107495.9 \mathrm{kcal} / \mathrm{mol}$

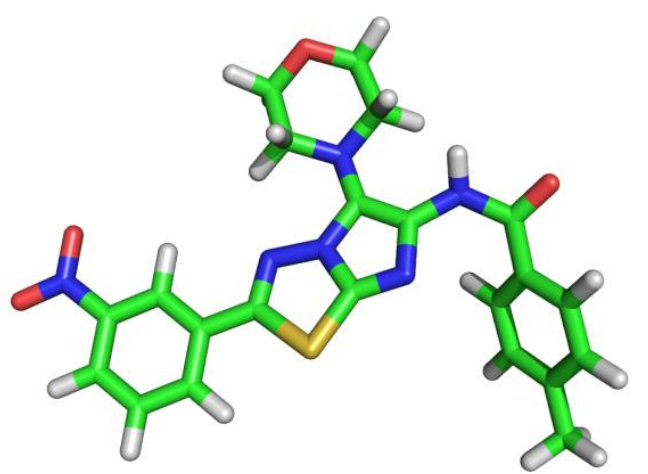

2f $\Delta \mathrm{G}=-120910.6 \mathrm{kcal} / \mathrm{mol}$

Figure S3. Structures of compounds 2 a-f and E260 optimized within the framework of the PM3 semiempirical method in the ArgusLab 4.0.1 software package. 
Table S1. Structures of $N$-(5-morpholino-2-arylimidazo[2,1-b][1,3,4]thiadiazol-6-yl)carboxamides (2a-f) and E260.

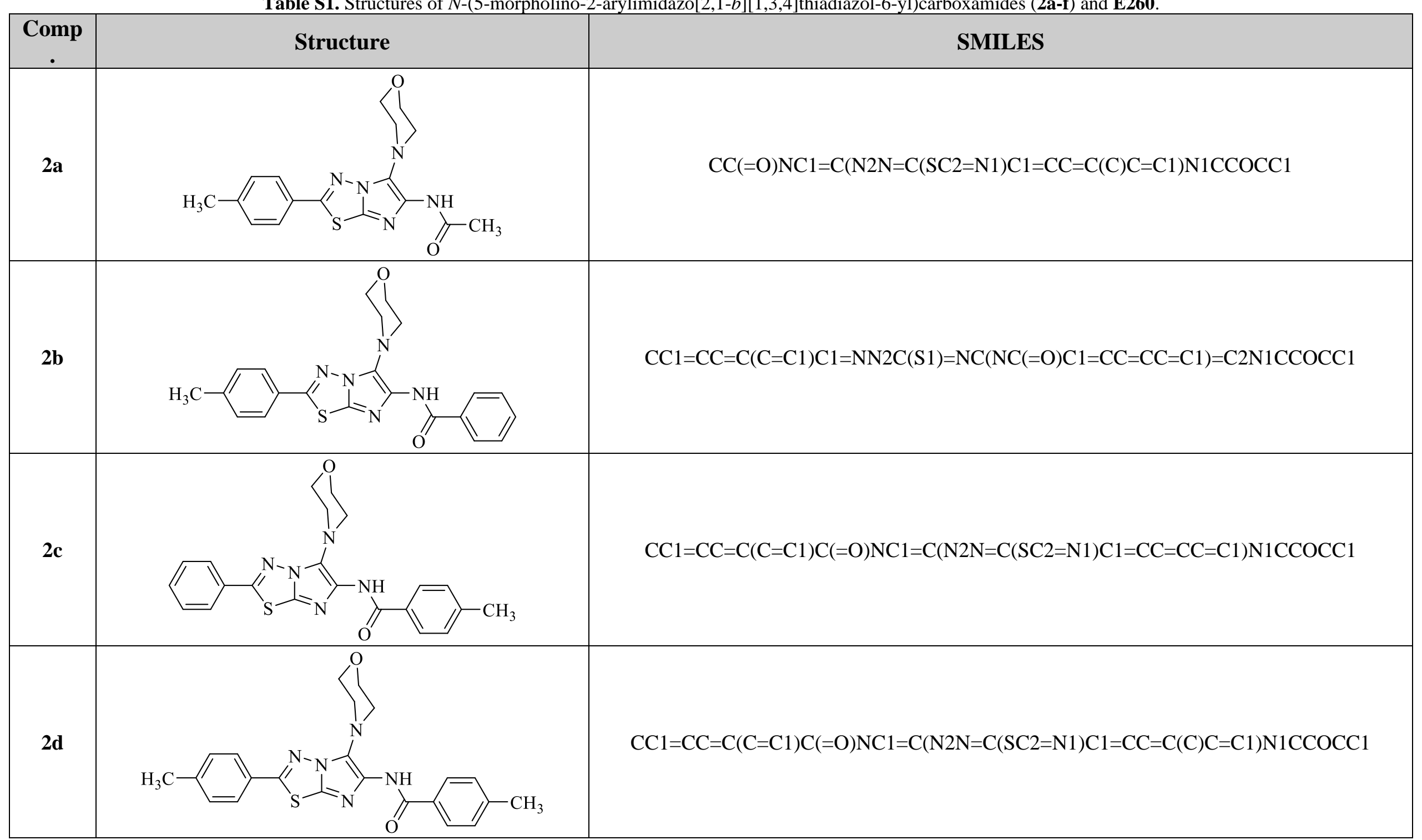




Comp


Table S2. Verification of $N$-(5-morpholino-2-arylimidazo[2,1-b][1,3,4]thiadiazol-6-yl)carboxamides (2a-f) and E260 for compliance with Lipinsky criteria* .

\begin{tabular}{|c|c|c|c|c|c|}
\hline Compound & $\mathrm{Mr}$ & $\log P$ & Rot.Bond & $\mathbf{H}_{\text {donor }}$ & $\mathbf{H}_{\text {acceptor }}$ \\
\hline $2 a$ & 357.44 & 2.56 & 3 & 1 & 7 \\
\hline $2 b$ & 419.51 & 3.86 & 4 & 1 & 7 \\
\hline $2 c$ & 419.51 & 3.86 & 4 & 1 & 7 \\
\hline $2 d$ & 433.54 & 4.16 & 4 & 1 & 7 \\
\hline $2 e$ & 498.41 & 4.62 & 4 & 1 & 7 \\
\hline $2 f$ & 464.51 & 3.76 & 5 & 1 & 9 \\
\hline E260 & 438.65 & 4.05 & 5 & 0 & 7 \\
\hline
\end{tabular}

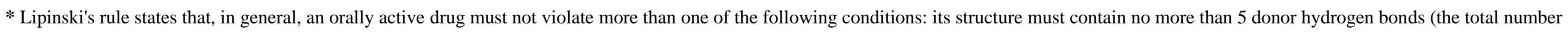

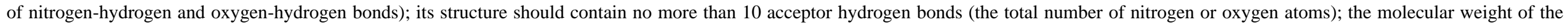
compound must be less than 500 a.e.m.; octanol-water partition coefficient $(\log \mathrm{P})$ should not exceed 5 for a given compound.

Table S3. In Silico evaluation of absorption and distribution properties of $N$-(5-morpholino-2-arylimidazo[2,1- $b][1,3,4]$ thiadiazol-6-yl)carboxamides (2a-f) and E260.

\begin{tabular}{|c|c|c|c|c|c|c|c|c|c|c|c|c|}
\hline \multirow{2}{*}{ Comp. } & \multicolumn{2}{|c|}{ Human oral bioavailability } & \multicolumn{2}{|c|}{ Human intestinal absorption } & \multicolumn{2}{|c|}{ Pgp-inhibitor } & \multicolumn{2}{|c|}{ Pgp-substrate } & \multicolumn{2}{|c|}{ Blood brain barrier } & \multicolumn{2}{|c|}{ Plasma protein binding } \\
\hline & result & prob. & result & prob. & result & prob. & result & prob. & result & prob. & result & $f_{b}, \%$ \\
\hline $2 \mathbf{a}$ & + & 0.5571 & + & 0.9364 & + & 0.6722 & - & 0.7046 & + & 0.9816 & + & 0.928 \\
\hline $2 \mathbf{b}$ & + & 0.5571 & + & 0.9404 & + & 0.9014 & - & 0.7214 & + & 0.9826 & + & 1.195 \\
\hline $2 c$ & + & 0.5857 & + & 0.9404 & + & 0.8897 & - & 0.6683 & + & 0.9826 & + & 1.181 \\
\hline 2d & + & 0.5857 & + & 0.9404 & + & 0.8826 & - & 0.6540 & + & 0.9816 & + & 1.086 \\
\hline $2 e$ & + & 0.6286 & + & 0.9251 & + & 0.8739 & - & 0.5670 & + & 0.9826 & + & 1.200 \\
\hline $2 f$ & + & 0.5857 & + & 0.9306 & + & 0.6722 & - & 0.7046 & + & 0.9742 & + & 1.181 \\
\hline E260 & + & 0.6286 & + & 0.9948 & + & 0.6819 & + & 0.7474 & + & 0.9951 & + & 0.902 \\
\hline
\end{tabular}


Table S4. In Silico evaluation of the metabolic pathways of $N$-(5-morpholino-2-arylimidazo[2,1-b][1,3,4]thiadiazol-6-yl)carboxamides (2a-f) and E260.

\begin{tabular}{|c|c|c|c|c|c|c|c|c|c|c|c|c|c|c|c|c|}
\hline \multirow[t]{2}{*}{ Comp. } & \multicolumn{2}{|c|}{$\begin{array}{c}\text { CYP3A4 } \\
\text { substrate }\end{array}$} & \multicolumn{2}{|c|}{$\begin{array}{c}\text { CYP2C9 } \\
\text { substrate } \\
\end{array}$} & \multicolumn{2}{|c|}{$\begin{array}{c}\text { CYP2D6 } \\
\text { substrate }\end{array}$} & \multicolumn{2}{|c|}{$\begin{array}{c}\text { CYP3A4 } \\
\text { inhibition }\end{array}$} & \multicolumn{2}{|c|}{$\begin{array}{c}\text { CYP2C9 } \\
\text { inhibition }\end{array}$} & \multicolumn{2}{|c|}{$\begin{array}{l}\text { CYP2C19 } \\
\text { inhibition }\end{array}$} & \multicolumn{2}{|c|}{$\begin{array}{c}\text { CYP2D6 } \\
\text { inhibition }\end{array}$} & \multicolumn{2}{|c|}{$\begin{array}{c}\text { CYP1A2 } \\
\text { inhibition }\end{array}$} \\
\hline & result & prob. & result & prob. & result & prob. & result & prob. & result & prob. & result & prob. & result & prob. & result & prob. \\
\hline $2 a$ & + & 0.5591 & - & 0.8000 & - & 0.8963 & + & 0.6808 & + & 0.8033 & - & 0.6448 & - & 0.9395 & - & 0.6641 \\
\hline $2 \mathrm{~b}$ & + & 0.5656 & - & 1.0000 & - & 0.9043 & - & 0.667 & + & 0.7410 & - & 0.7069 & - & 0.9070 & - & 0.6051 \\
\hline $2 c$ & + & 0.5571 & - & 1.0000 & - & 0.9043 & - & 0.667 & + & 0.7410 & - & 0.7069 & - & 0.9070 & - & 0.6051 \\
\hline $2 d$ & + & 0.5593 & - & 1.0000 & - & 0.9043 & - & 0.6808 & + & 0.8033 & - & 0.6448 & - & 0.9395 & - & 0.6641 \\
\hline $2 e$ & + & 0.6113 & - & 1.0000 & - & 0.8989 & - & 0.5067 & + & 0.8559 & + & 0.6347 & - & 0.8722 & + & 0.5614 \\
\hline $2 f$ & + & 0.6515 & - & 0.7932 & - & 0.8979 & + & 0.8827 & + & 0.6648 & - & 0.6259 & - & 0.9325 & - & 0.8013 \\
\hline E260 & + & 0.6127 & - & 0.8046 & + & 0.5327 & - & 0.9587 & - & 0.6537 & - & 0.5739 & - & 0.5151 & + & 0.5474 \\
\hline
\end{tabular}

Table S5. In Silico toxicity evaluation of $N$-(5-morpholino-2-arylimidazo[2,1- $b][1,3,4]$ thiadiazol-6-yl)carboxamides (2a-f) and E260.

\begin{tabular}{|c|c|c|c|c|c|c|c|c|}
\hline \multirow{2}{*}{ Comp. } & \multicolumn{2}{|c|}{ Acute oral toxicity } & \multicolumn{2}{|c|}{ hERG blockers } & \multicolumn{2}{|c|}{ Hepatotoxicity } & \multicolumn{2}{|c|}{ BSEP inhibitior } \\
\hline & $-\log \mathrm{mol} / \mathrm{kg}$ & $\mathrm{mg} / \mathrm{kg}$ & result & prob. & result & prob. & result & prob. \\
\hline $2 a$ & 2.163 & 2455.9 & + & 0.6781 & + & 0.8250 & + & 0.6528 \\
\hline $2 \mathbf{b}$ & 2.422 & 1587.6 & + & 0.7769 & + & 0.7750 & + & 0.8602 \\
\hline $2 c$ & 2.369 & 1793.7 & + & 0.8280 & + & 0.8000 & + & 0.8346 \\
\hline 2d & 2.489 & 1406.1 & + & 0.8210 & + & 0.7750 & + & 0.8623 \\
\hline $2 e$ & 2.414 & 1921.3 & + & 0.8203 & + & 0.8000 & + & 0.8995 \\
\hline $2 f$ & 2.254 & 2588.2 & - & 0.6297 & + & 0.6500 & + & 0.9207 \\
\hline E260 & 3.263 & 239.4 & + & 0.8927 & + & 0.5250 & + & 0.9489 \\
\hline
\end{tabular}

